\title{
Enriching Individual Absorptive Capacity
}

\section{Introduction}

Absorptive capacity (AC hereafter) is conceptualized as a dynamic capability (Lewin et al., 2011, Volberda et al., 2010) enabling a firm to acquire, process, apply and exploit external knowledge (Cohen and Levinthal, 1990). Extending this dynamic nature further, Zahra and George's (2002) seminal paper distinguishes AC exists as two separate but complementary subsets of potential (knowledge acquisition and assimilation) and realized AC (knowledge transformation and exploitation). Research has shown that $\mathrm{AC}$ contributes towards organizational learning processes and outcomes, such as knowledge transfer (Minbaeva et al., 2014), innovation and financial performance (Soo et al., 2002; Volberda et al., 2010; Zahra and George, 2002). Conceptually, although Cohen and Levinthal (1990, p. 131-135) explicitly argued that a firm's AC has both individual and organizational antecedents, empirical AC research has largely focused on aggregate collective-level relationships, such as country, interand intra-organizational levels of analysis (e.g., Lane et al., 2006; Volberda et al., 2010). To address the multilevel nature of AC, there has been a growing body of research calling for an improved understanding of the micro-foundations of AC (Foss, 2011; Lane et al., 2006; Lewin et al., 2011; Minbaeva et al., 2014; Volberda et al., 2010). For instance, Volberda et al. (2010, p. 944) stated that "the understanding of AC as a dependent variable, absent of a consideration of the level of individuals and their action, may be inherently incomplete". This is because a firm's AC “depends on the individual absorptive capacities of the organization's members" (Lane et al., 2006, p. 838). In more recent years, scholars have examined the link between a firm's AC and a number of individual-level behaviors or characteristics, including organizational citizenship behavior (Hart et al., 2016), individual learning orientation and behavior (Martinkenaite and Breunig, 2016; Yao and Chang, 2017), social interaction (Hotho et al., 2012; Tortoriello, 2015), and leadership (Flatten et al., 2015). 
Despite calls for more attention to the role of individual-level antecedents to AC, this issue remains under-addressed (Hart et al., 2016). To date, only a few studies have conceptualized and tested when and how individual level antecedents could be linked with firm AC (e.g., Flatten et al., 2015; Hotho et al., 2012; Yao and Chang, 2017). For example, adapting the bottom-up approach, Yao and Chang (2017) find that two individual-level characteristics, individual learning goal orientation and civic virtue, can contribute to the development of firm potential and realized AC. While these studies have advanced our understanding of how individual-level $\mathrm{AC}$ can contribute to firm $\mathrm{AC}$, however, the development of $\mathrm{AC}$ at the individual level remains unclear. This void is surprising when we consider that scholars have long argued that, in order to understand firm $\mathrm{AC}$, one must necessarily examine the $\mathrm{AC}$ of the employees in question (Jansen et al., 2005; Volberda et al., 2010; Zahra and George, 2002). Thus in this study, following calls for more empirical studies on individual level AC (e.g., Volberda et al., 2010; Yao and Chang, 2017), and a better understanding of how it is developed (e.g., Flatten et al., 2015; Soo et al., 2016), we explore the antecedents and consequences of $\mathrm{AC}$ at the individual level.

The key objectives of this study are two-fold. First, we respond to calls for a better understanding of $\mathrm{AC}$ development at the individual level by examining two antecedents (i.e., intrinsic motivation and perceived organizational commitment to learning) of individual AC. Intrinsic motivation, which refers to doing something because it is inherently interesting or enjoyable (Ryan and Deci, 2000), has been shown to be a key motivational force that leads to learning, knowledge sharing and creativity (Reinholt et al., 2011). Perceived organizational commitment to learning is defined as the degree to which an organization values and promotes learning (Sinkula et al., 1997). Calantone et al. (2002, p. 515) suggest that the more an organization values learning, the more likely it is that its employees will be engaged in learning activities. While the concept of commitment to learning has been typically studied at 
organizational level (Calantone et al., 2002; Kukenberger et al., 2015), we contend that, at the individual level, it is employees' perception of organizational commitment to learning that has a close relationship with employees' learning behaviors and outcomes. Taken together, we echo Minbaeva and colleagues' argument that individuals are heterogeneous: they differ in various aspects of motivation and how they respond to external cues for learning and knowledge sharing - and that these differences reflect their respective AC (Minbaeva et al., 2012). Second, in addition to the antecedents of individual level AC, we also examine the outcomes of individual AC by examining its influence on employees' creativity and job performance, as both represent important sources of organizational innovation and competitive advantage (Gong et al., 2013; Martinaityte and Sacramento, 2013; Zhou and Shalley, 2011). Furthermore, we examined the dual role of realized $\mathrm{AC}$ as a mediator in the employee potential $\mathrm{AC}$-creativity relationship, and as a moderator on the creativity-job performance relationship.

In summary, while AC has been largely studied at the collective-level as an independent variable, it has, by definition, a strong foundation at the individual level (Cohen and Levinthal, 1990). As Lane et al. (2006) argued, a firm's AC depends on the absorptive capacities of the organization's members. Yet surprisingly little attention has been devoted to understanding how $\mathrm{AC}$ is developed at the individual level, and how individual $\mathrm{AC}$ can have a positive impact on employees' creativity and job performance. Thus, drawing from the wealth of studies that have looked at AC from the collective level (i.e., business unit and/or organizational level), in this paper, utilizing matched employee-supervisor data at the individual level, we focus on the two antecedents (i.e., intrinsic motivation and perceived organizational commitment to learning) and consequences (i.e., employee creativity and job performance) of individual AC.

\section{Theoretical background and hypotheses development}

\section{Absorptive capacity at the individual level}


According to the seminal work of Cohen and Levinthal, AC is defined as the "ability of the firm to recognize the value of new, external information, assimilate it, and apply it to commercial ends" (1990, p. 128). The concept was extended by Zahra and George (2002), who distinguished four dimensions of $\mathrm{AC}$, each playing different but complementary roles in explaining how AC influences organizational performance. These dimensions are acquisition (the ability to identify and acquire critical external knowledge), assimilation (the ability to analyse, process, interpret and understand the obtained external knowledge), transformation (the ability to modify and adapt external knowledge and combine new and existing knowledge to gain new insights and perspectives), and exploitation (the ability to incorporate the newly acquired and transformed knowledge into the firm's competitive advantage).

Zahra and George (2002) propose that the first two dimensions form a firm's potential AC, which makes a firm receptive to external knowledge flows, while the other two constitute a firm's realized AC, which reflects the efficiency in leveraging externally absorbed knowledge and transforming it into performance outcomes. With regard to the organizational outcomes, research has stressed that potential AC can be seen as the ability to detect relevant knowledge and store it in the organizational memory; thus it is not necessarily a direct driving force for organizational performance in itself. In contrast, realized AC involves capabilities of exploiting relevant knowledge and realizing commercial gains with it, and thus it is expected to enhance firm performance (Flatten et al., 2015; Zahra and George, 2002). The categorization of potential and realized AC is consistent with prior theory and empirical studies which suggest that they are theoretically and empirically distinguishable (e.g., Jansen et al., 2005; Camisón and Forés, 2010). As their effect is complementary rather than mutually exclusive, they must exist simultaneously in order to achieve the optimal performance results (Zahra and George, 2002). The distinction is important because new knowledge has to be identified and assimilated first (i.e., potential AC) before it can be transformed and exploited (i.e., realized AC). 
In this study, we examine both potential and realized $\mathrm{AC}$ at the individual level. Staying close to the original definition by Cohen and Levinthal (1990), we define individual-level AC as the individual's ability to identify external knowledge, and to assimilate and utilize it to generate performance benefits. In accordance with Zahra and George's (2002) assertion, we posit that, at the individual level, the ability to acquire and assimilate knowledge (i.e., potential AC) may not necessarily imply better performance outcomes (i.e., creativity and task performance), unless it leads to higher levels of realized AC. We draw on theoretical insight from Ployhart and Moliterno’s (2011) emergence-enabling process of human capital resources, and suggest that firm AC is a human capital resource that is developed through the individuallevel AC of the employees who make up the firm. This is consistent with Foss' (2007) argument that organizational knowledge processes "cannot be reached in lieu of a starting point in individuals" (p. 43). Thus, consistent with Ployhart and Moliterno's (2011) proposition, we suggest that more attention should be paid to exploring antecedents and outcomes of AC at the individual level. We do not argue that firm AC should not be treated as an aggregation of individual AC. Rather, we suggest that firm AC originates in its employees, and "is amplified by their interactions, and manifests as a higher-level, collective phenomenon" (Kozlowski and Klein, 2000, p. 55). Thus, more attention should be paid to the development and consequences of AC at the individual level of analysis.

\section{Antecedents and outcomes of individual AC}

\section{Linking individual intrinsic motivation and potential AC}

We first posit that intrinsic motivation positively affects individual employees' engagement in knowledge acquisition and assimilation (i.e., potential AC). Conceptually, researchers have suggested that firm $\mathrm{AC}$ has a foundation rooted in an understanding of individual motivation, cognition, action, and interaction (Volberda et al., 2010). Empirically studies have also tested 
the role of motivation in the knowledge creation and transfer process (e.g., Bock et al., 2005; Gagné, 2009; Minbaeva et al., 2003; Minbaeva et al., 2012; Reinholt et al., 2011). For example, Minbaeva et al. (2003) tested the role of overall motivation of a subsidiary's employees on knowledge transfer. While the authors did not find a direct positive effect of motivation upon knowledge transfer, they found that the interaction between a subsidiary's overall motivation and ability had a strong positive impact on knowledge transfer.

We examine the role of motivation by drawing on Self Determination Theory (SDT), which states that individuals' behavior varies with respect to two broad types of motivation: intrinsic motivation, which comes from within the individual, and refers to doing something because it is inherently interesting or enjoyable; and extrinsic motivation, which refers to doing something because it leads to a separable outcome such as monetary rewards (Deci and Ryan, 2012; Gagné and Deci, 2005; Ryan and Deci, 2000). Intrinsic motivation is often argued to lead to more persistent behavioral effort, which in turn results in more positive outcomes than does extrinsic motivation. The motivation research shows that individuals who are intrinsically motivated to learn and to do their work are more likely to actively seek knowledge from others (e.g., Reinholt et al., 2011), and engage in knowledge sharing behavior (e.g., Foss et al., 2009; Minbaeva et al., 2012; Reinholt et al., 2011). The intrinsic value of personal knowledge growth is a strong motivator for individuals to acquire and assimilate knowledge (i.e., potential AC) irrespective of other forms of tangible rewards for knowledge application (Bock et al., 2005). While extrinsic motivation is also an important factor influencing individual's engagement in knowledge seeking and sharing behavior, the empirical results are mixed. While some have found support for a positive extrinsic motivation and knowledge sharing/exchange relationship (e.g., Cabrera and Cabrera, 2005; Minbaeva et al., 2012), others have reported a negative relationship (e.g., Bock et al., 2005; Foss et al., 2009). It is noteworthy that, while research taking the SDT perspective has unambiguously argued that intrinsic motivation is superior to 
extrinsic motivation in influencing individuals outcomes such as knowledge sharing, task performance and creativity (e.g., Zhang and Bartol, 2010b), few studies have included both types of motivation or empirically examined their differential effects.

Addressing this gap, we investigated the role of intrinsic motivation on individuals' potential AC, controlling for extrinsic motivation. Although no study has specifically investigated the role of motivation upon individual potential AC, existing empirical evidences provide the theoretical rationale for the link between intrinsic motivation and employees' knowledge acquisition and assimilation (i.e., potential AC). In keeping with well-established motivation research (Deci and Ryan, 2000), we argue that intrinsically motivated individuals are more likely to engage in knowledge acquisition and assimilation behaviors because they will feel a sense of pleasure or satisfaction derived from these behaviors. More importantly, this positive effect should remain, even when the effect of extrinsic motivation is controlled.

Hypothesis 1. The employee intrinsic motivation accounts for the prediction of employee potential AC, that is, above and beyond the effect of extrinsic motivation.

\section{Linking perceived organizational commitment to learning and potential AC}

In addition to individual-level antecedents, researchers have increasingly focused on how employees' perception of organizational contextual factors influence their behavior, such as creativity and knowledge seeking and sharing (e.g., Hirst et al., 2011; Hirst et al., 2009). For example, Hirst et al. (2009) stated that individual behaviors are often enacted in organizational and team settings, and thus it is critical to understand how and to what extent perceived contextual factors influence an employee's behaviors. This is consistent with the key premise underlying theories of person-situation interactions, such as social learning theory (Rosenthal and Zimmerman, 1978), in which individuals analyse, react to, and influence their environment according to their dispositions. Drawing theoretical insights from these theories, we propose that the perception of organizational commitment to learn could be seen as "individual 
conditions of action" (Minbaeva et al., 2012), which influences individual behaviors. According to Sinkula et al. (1997), organizational commitment to learning reflects the degree to which an organization values and promotes learning. For instance, Mavondo et al. (2005) asserted that organizational commitment to learning is the manifestation of the organization's capacity and propensity to learn. A strong organizational commitment to learning is likely to foster an organizational climate that encourages organizational members to engage in knowledge creation and sharing activities (Baker and Sinkula, 1999; Li et al., 2010; Mavondo et al., 2005; Sinkula et al., 1997). At the individual level, organizational learning theory suggests that organizations with strong commitment to learning encourage and value employees' continuous efforts to identify and acquire, share and utilize knowledge to improve performance (Baker and Sinkula, 1999; Sinkula et al., 1997). Given that organizational commitment to learning is concerned with "the development of new knowledge in the organization" (Li et al., 2010, p. 84), we therefore posit that an individual who perceives a greater level of organizational commitment to learning is more likely to behave in ways that are aligned with such norms and expectations (i.e., engage in knowledge acquisition and assimilation).

To the best of our knowledge, there is no empirical work that has tested the relationship between perceived organizational commitment to learning and individual potential AC. A related study by Minbaeva et al. (2012) found that employee engagement in knowledge exchange is dependent upon the extent to which the individual believes whether it is a valued activity as considered by his/her immediate group and/or the organization as a whole. Although that study focused on perceived organizational commitment for knowledge sharing rather than perceived organizational commitment for learning, it provides a strong theoretical rationale for a positive relationship between perceived organizational commitment to learning and individual AC. Thus, we believe that in a strong climate that is characterised by high commitment to 
continuous learning and development, individual employees are more encouraged to engage in knowledge acquisition and assimilation behaviors.

Hypothesis 2: Individual employees' perceived organizational commitment to learn is positively related to individual employees' potential AC.

\section{Integrating Potential AC, realized AC and creative performance}

With regard to the relationship between potential AC, realized AC and creativity, we build upon Zahra and George's (2002) argument that, in order for firms to transform and exploit new knowledge (i.e., realized AC) to generate creativity, they must first have the capabilities to acquire and assimilate (i.e., potential AC) new knowledge. Zahra and George (2002) assert this distinction very clearly: "a high PACAP (potential AC) does not necessarily imply enhanced performance. RACAP (realized AC) involves transforming and exploiting the assimilated knowledge by incorporating it into the firm's operations, thereby improving its performance.... Despite the importance of PACAP, RACAP is the primary source of performance improvements" (p. 191). At the organizational level, empirical research has also demonstrated that potential $\mathrm{AC}$ contributes to organizational innovation through the effect of realized $\mathrm{AC}$ (e.g., Soo et al., 2016).

In this study, we adapt the potential $\mathrm{AC}$ - realized $\mathrm{AC}$ - organizational innovation relationship to the individual level of analysis, and argue that there is a positive relationship between potential and realized $\mathrm{AC}$, and that individuals have to acquire knowledge first before they can exploit it to improve their creativity. Creativity refers to the production of novel and useful ideas concerning products, services, processes and procedures (Amabile, 1996). We focus on creativity as a critical individual performance outcome, because scholars have frequently argued that employee creativity is positively associated with work-related outcomes, such as individual job performance, and organizational survival and competitiveness (e.g., George and Zhou, 2002; Gong et al., 2013; Hirst et al., 2009; Zhang and Bartol, 2010a). 
With regard to the relationship between potential $\mathrm{AC}$, realized $\mathrm{AC}$ and creative performance, we argue that, rather than a direct antecedent employee creative, the potential ACcreativity relationship is mediated through realized AC (e.g., Jansen et al., 2005; Zahra and George, 2002). To the best of our knowledge, there is no published research that has tested the indirect relationship between individual potential AC, realized $\mathrm{AC}$ and creativity. To address this gap in the literature, we build on Zahra and George's (2002) arguments and hypothesize that individual employees' ability to acquire and assimilate knowledge (i.e., potential AC) will not necessarily lead to more creativity without the new knowledge being transformed and exploited (i.e., realized AC).

Hypothesis 3: There is an indirect effect from individual employees' potential AC to their creativity via individual employees' realized AC.

\section{Integrating realized $A C$, employee creativity and job performance}

In more recent years, scholars have argued that, while much research has focused on the determinants of creativity (for recent reviews, see Anderson et al., 2014; Zhou and Shalley, 2011), significantly less attention has been paid to the outcomes of creativity (e.g., Gong et al., 2009; Gong et al., 2013; Martinaityte and Sacramento, 2013; Zhang and Bartol, 2010a). This limited attention is surprising, given that a key assumption in the creativity literature is that employee creativity is beneficial for individual and organizational outcomes (Gilson, 2008; Zhou and Shalley, 2011). As Gong et al. (2009) put it, creativity is only "of value to organizations ... to the extent that it impacts employee job performance" (p. 765). To date, limited studies have investigated the creativity and job performance relationship, and have mostly reported a positive association (e.g., Gong et al., 2009; Zhang and Bartol, 2010a). However, very little is known about the conditions under which employee creativity is more or less likely to lead to job performance at the individual level of analysis. One exception is provided by Martinaityte and Sacramento (2013), who found that high quality of leader- 
member exchange enhanced the effect of employees' creativity on sales effectiveness. Another firm-level example is provided by Gong et al. (2013). At the firm level, Gong et al. provide support to the notion that, rather than a direct relationship, the aggregated employee creativity and firm performance relationship was contingent upon the aggregated measure of core knowledge employees' ability to transform and exploit new knowledge (i.e., realized AC).

Thus, in this study, we respond to research calling for further study to not only understand the connection between creativity and job performance, but, more importantly, to understand the boundary conditions under which employee creativity is more or less likely to lead to better job performance (e.g., Gong et al., 2013; Martinaityte and Sacramento, 2013). Specifically, inspired by Gong et al.'s (2013, p. 454) argument that, for creative ideas to be translated into improved performance, the capacity of "employees to transform and exploit creative ideas is critical", we posit that individual employees' creativity should interact with their realized AC to jointly affect job performance. Although Gong et al.'s study focused on firm-level measures, it is reasonable to believe that the moderating role of realized AC is equally importantly at the individual level of analysis. That is, employee creativity does not drive performance directly unless it is transformed and implemented. By focusing on realized AC at the individual level, we test the critical moderating role of individuals' realized $\mathrm{AC}$ in enhancing the positive creativity-job performance relationship.

Hypothesis 4. Individual employees' realized AC moderates the impact of employee creativity to job performance, such that the impact is stronger when realized AC is high and weaker when realized $\mathrm{AC}$ is low.

\section{Methods}

\section{Sample and data collection procedures}


We draw our sample from employees working in a major Chinese automotive design firm where learning, creativity and innovation are considered important. In consultation with the organization's human resource managers, we selected employees and their immediate supervisors from multiple departments in the organization. For data collection, we conducted two-wave, multiple-source, on-site surveys at an average four-week interval. Specially, at Time 1, employees reported their perception of organizational commitment to learning, intrinsic motivation, potential AC and control variables (e.g., demographic variables of age, education and organizational tenure, and anticipated extrinsic reward for knowledge seeking and sharing activities). At Time 2, we asked employees to rate their realized AC, and we asked the supervisors to rate employee creativity and job performance. Each supervisor was asked to rate one follower's creativity and job performance. A total of 125 (48\% response rate) independent paired useable responses were received. The sample consists mostly of employees aged between 20 and 29 (75.2 per cent), female (76.8 per cent), and highly educated (50.4 per cent held a diploma degree or above).

\section{Measures}

All materials were presented in Chinese. Questions were translated from English into Chinese by the author, who is fluent in both languages. To maximize translation equivalence, the final Chinese text was back-translated into English by a bilingual research assistant.

Individual Absorptive Capacity. This was measured using an 18-item used by Soo et al. (2016). The four-item acquisition scale assessed an individual's ability to identify and obtain new external knowledge. The five-item assimilation scale assessed an individual's ability to develop processes and routines useful in analysing, interpreting and understanding newly acquired external knowledge. The five-item scale transformation measured how individuals were able to develop routines to facilitate the combination of existing knowledge with the newly 
acquired and assimilated knowledge to form new knowledge or insights. The four-item exploitation scale assessed how individuals were able to apply and exploit new external knowledge to improve the current work processes and procedures. Potential AC is measured by the acquisition and assimilation scale, while realized $A C$ is measured by the transformation and exploitation scale. The Cronbach's alpha was .79 for potential AC, and .89 for realized AC.

Perceived Organizational Commitment to Learning. This was measured using a four-item scale adapted from Sinkula et al. (1997). A sample item is "The basic values of this organization include learning as key to improvement”. The Cronbach's alpha was .87.

Intrinsic Motivation. This was measured by a four-item scale used by Reinholt et al. (2011). Following Reinholt et al.'s approach, respondents were asked "Why do you share knowledge?" and were given four possible answers. Sample items are “... because I find it personally satisfying” and “... because I enjoy it”. The Cronbach's alpha was .72.

Creativity. This was measured using a nine-item scale adapted from Tierney et al. (1999). Supervisors were asked to rate their subordinates' creativity a five-point scale ranging from "never" to "almost always". A sample item is "This employee demonstrates originality in his/her work". The Cronbach's alpha was .93.

Job Performance. This was measured with a seven-item scale from Williams and Anderson (1991). Supervisors were asked to rate their subordinates' job performance on a fivepoint scale ranging from "never" to "almost always". A sample item is "This employee adequately completes assigned duties". The Cronbach's alpha was .91.

Control Variables. We controlled for the demographic variables of age, education and organizational tenure, as these variables have been found to influence performance. Following Bock et al.'s (2005) approach, we controlled for two forms of extrinsic reward for knowledge seeking and sharing activities: first is the anticipated extrinsic rewards, which include monetary incentives and expected promotion; second is the anticipated reciprocal relationships, which 
capture employees' desires to maintain ongoing relationships with others, specifically with regard to knowledge provision and reception. Anticipated extrinsic reward is measured using four items which asking about whether employees will receive rewards or additional points for promotion in return for any knowledge sharing. A sample item is "I will receive monetary rewards in return for sharing knowledge in my company". The Cronbach's alpha was .79. Anticipated reciprocal benefits were measured using five items that are adapted from Bock et al. (2005). A sample item is "My knowledge sharing would strengthen the ties between existing members in the organization and myself'. The Cronbach's alpha was .88.

\section{Results}

\section{Descriptive statistics}

Descriptive statistics for the study variables are presented in Table 1. To detect potential issues of multicollinearity, we conducted a multiple linear regression model to obtain the variance inflation factor (VIF) for all variables. While different critical VIF values have been used as rules of thumb to indicate excessive or serious multicollinearity, a common rule of thumb is that if VIF $>10$, the multicollinearity is severe. The VIF values of independent variables ranged from 1.17 to 2.62 , indicating that the independent variables do not have a severe multicollinearity problem. Therefore, all variables were retained.

Insert Table 1 about here

\section{Hypothesis testing}

The results of the direct and the moderated hierarchical regression analyses associated with our hypotheses are summarized in Table 2. Based on Aiken and West (1991), all independent variables were mean-centered to reduce multicollinearity. To test Hypotheses 1 and 2, we conducted hierarchical regression analyses with potential AC as the dependent 
variable, entering first all controls (Model 1), and then included intrinsic motivation and perceived organizational commitment to learning as predictors (Model 2). As shown in Table 2, after controlling for extrinsic motivation, the coefficient for intrinsic motivation was significant $(\beta=.24, \mathrm{p}<.01)$. Thus, Hypothesis 1 was supported, as intrinsic motivation accounts for significant variations in employee potential AC. Furthermore, perceived organizational commitment to learning was significantly related to employee potential $\mathrm{AC}(\beta=.11, \mathrm{p}<.05)$, thereby supporting Hypothesis 2 . Thus, individuals who are more intrinsically motivated, and perceive high levels of organizational commitment to learning, are more willingly actively acquire and assimilate new knowledge at work.

Hypothesis 4 predicted that individuals' creative was more positively related to job performance when they also pose a higher level of realized AC. Results from Table 2 (Model 4) suggested that employee creative performance marginally predicted individuals' job performance $(\beta=.13, \mathrm{p}<.10)$. Before testing the interaction effects of realized $\mathrm{AC}$, we centered the independent variables to increase the interpretability of the interaction variable (Aiken \&West, 1991). We tested this hypothesis by adding the interaction between creative performance and realized AC (model 6). The results show that this interaction was not significant $(\beta=-.06, \mathrm{~ns})$. Therefore, Hypothesis 4 was not supported.

Insert Table 2 about here

To test Hypothesis 3, we followed Baron and Kenny's (1986) procedure, as well as the recommendation of Shrout and Bolger (2002) to test the indirect effect using a bias-corrected bootstrapping approach. First, we followed Baron and Kenny's (1986) procedure to present the total, direct and indirect effect between potential AC and creativity. In step 1, we regressed realized AC on employee creative. In step 2, we regressed employee creative on potential AC. In step 3, we regressed employee creative on potential AC and realized AC. In all of the above 
analyses, we controlled for age, gender, education level and organizational tenure. For ease of presentation, Table 3 summarizes the main results with the coefficient for control variables omitted. In steps 1 and 2, employee potential AC emerged as significant predictors of employee realized $\mathrm{AC}(\beta=.30, \mathrm{p}<.001)$, and employee creative $(\beta=.12, \mathrm{p}<.01)$. When employee realized $\mathrm{AC}$ was added to the equation in step 3, employee potential $\mathrm{AC}$ was no longer significant at the conventional level, but employee realized AC remained significant $(\beta=.44$, $\mathrm{p}<.001)$. Thus supported Hypothesis 3.

Although the Baron and Kenny's (1986) test showed significant mediating effect of realized $\mathrm{AC}$, it is still important to test the significance of these effects in a more rigorous manner (Rucker et al., 2011). Specifically, we followed the recommendation of Shrout and Bolger (2002) to test the indirect effect using a bias-corrected bootstrapping approach with the aid of a SPSS macro developed by Preacher and Hayes (2008). Bootstrapping involves the repeated and randomised extraction of samples from the dataset, calculating the indirect effect for each re-sample. A confidence interval (CI) is investigated for each indirect path to determine significance levels (Shrout and Bolger, 2002). If zero is not included within the range the confidence internals, it indicates a significant effect (Rucker et al., 2011; Shrout and Bolger, 2002). Accordingly, support was found for the relation of potential AC and creativity as mediated by realized $\mathrm{AC}$, the indirect effect was $.13(\mathrm{p}<.001 ; 95 \% \mathrm{CI}=.09-.22)$. As the indirect effect was significant and the 95\% CI around the bootstrapped indirect effect does not contain zero $(.09-.22)$, this again provide support to Hypothesis 3 .

Insert Table 3 about here

\section{Discussion}

Although previous research has considered AC as a main determinant of inter- and intraorganizational knowledge transfer, research focus on the individual level remains limited. Thus, 
in this study, staying close to Cohen and Levinthal's (1990) conceptualizations of AC, we focus on the individual level in order to better understand the antecedents and consequences of individual AC. In particular, we examined two direct relationships, including employees' perceptions of organizational commitment to learning and intrinsic motivation as predictors of their potential AC. We also examined the dual role of realized AC as a mediator in the employee potential AC-creativity relationship, and as a moderator on the creativity-job performance relationship. Our results lead to three main conclusions. First, employees' perception of organizational commitment to learning and intrinsic motivation to knowledge sharing contributes positively to their potential AC, even when their extrinsic motivation was controlled for. Second, employees' potential AC relate positively to their creative performance through their influence on employees' realized AC. Third, although we did not hypothesize a direct relationship between employee creativity and job performance, our results also provided support to this often-assumed but less-investigated relationship. Fourth, contrary to our hypotheses, we did not find support for the moderating role of realized AC upon the employee creativity-job performance relationship.

\section{Theoretical implications}

Our research makes three distinct theoretical contributions. First, we contribute to the AC literature by responding to the calls for more research focus at the individual level (e.g., Minbaeva et al., 2012; Volberda et al., 2010). An individual level of analysis is considered important and essential, because individuals are considered as primary actors in knowledge creation and key repositories of knowledge in organizations. Specifically, drawing upon SDT theory (Gagné and Deci, 2005; Ryan and Deci, 2000), we provide empirical support that individuals' $\mathrm{AC}$ is influenced by their intrinsic motivation (over and above extrinsic motivation) and their perception organizational commitment to learning. In doing so, we provide a micro- 
level analysis that is complementary to the dominant macro-level analysis in the AC research (Minbaeva et al., 2012). Taking the SDT perspective, much research has unambiguously assumed that intrinsic motivation is superior to extrinsic motivation in influencing individuals' performance outcomes. In this study, we provide empirical evidence that individual intrinsic motivation provides meaningful variance in employees' potential AC that is above and beyond that predicted by extrinsic motivation. Our findings support recent research highlighting that individual behaviors are often enacted within unique organizational settings, and thus it is critical to understand how and to what extent contextual factors (e.g., organizational commitment to learning) influence employees' behaviors (e.g., Hirst et al., 2011).

Second, taking a micro approach, we found that employee realized AC significantly mediated the relationship between their potential AC and creativity. This significant mediation result provides empirical support to the PAC-RAC-performance argument made by Zahra and George (2002) at the organizational level. Conceptually, they assert that "despite the importance of PACAP (potential AC), RACAP (realized AC) is the primary source of performance improvements" (Zahra and George, 2002, p. 191). Empirically, researchers such as Chang et al. (2013) posited that a high level of realized AC helps a firm leverage their current resources to transfer the valuable knowledge, which in turn leads to enhanced firm innovativeness. However, the authors did not find support for a mediation role of RAC. Therefore, this study takes an important step toward a better understanding of how the positive impact of potential $\mathrm{AC}$ on realized $\mathrm{AC}$ ultimately influences creativity. Our results provide evidence for the importance of individual-level learning in the process of knowledge creation, sharing and utilization, a concept at the core of the knowledge-based view of the firm.

Finally, it provides an empirical contribution to a promising direction for creativity research (Martinaityte and Sacramento, 2013; Zhang and Bartol, 2010a; Zhou and Shalley, 2011). Creativity research has thus far focused predominantly on understanding the antecedents 
of creativity, with very little attention given to understanding how it affects important work outcomes such as job performance. While we did not specifically hypothesize a direct relationship between employee creativity and job performance, our results provide empirical support to this less studied area. And although we did not find a significant moderating role of RAC in the creativity-job performance relationship, this study takes a step towards understanding the boundary conditions under which creativity can be translated into superior job performance. This is important because, as Martinaityte and Sacramento (2013) pointed out, "virtually nothing is known about the conditions under which employee creativity is more or less likely to lead to job effectiveness" (p. 974).

\section{Managerial implications}

This study offers several managerial implications. The first is that our study speaks directly to the question of how an organization can prepare and encourage its employees to absorb new knowledge. We show that an organization should not emphasize simply extrinsic rewards (i.e., salary incentives and bonuses) as a primary knowledge sharing motivation, because these may only provide temporary incentives for knowledge sharing. Instead, organizations should design their HR policies and practices to focus on establishing a positive organizational climate for continuous learning and enhancing employees' intrinsic motivation (Gagné, 2009), as they are some of the key drivers to enhance employees' ability to acquire and to process newly acquired knowledge (i.e., potential AC). For example, with regard to perception of organizational commitment to learning, HR practices can be developed in areas such as selection, job design, training and development, performance management, compensation systems to facilitate the establishment and maintenance of a shared perception of organizational commitment to learning. In terms of selection, it is possible that organizations could be benefit by selecting employees to exhibit a passion and leadership style that helps 
facilitates learning. For example, leaders are considered to be more transformational, empowering and supportive could help employees to focus on continuous learning. In terms of training, not only HR practices should continue to focus on utilize formal training programs to promote learning norms, but also other forms of learning programs (e.g., coaching, mentorship, on-demand training) should be highly encouraged.

With regard to intrinsic motivation, HR practices can be developed in areas such as job design, training and development, performance management, compensation systems to promote intrinsic motivation. For example, in terms of performance appraisal, indicators of employees' continuous learning and ability to absorb and apply new knowledge should be incorporated into performance appraisals with a developmental focus rather than an administrative focus (i.e., evaluative in nature). A developmental focus appraisal have been shown to enhance intrinsic motivation and employee commitment (Aguinis, 2013; Kuvaas, 2007).

Second, we show that, while it is of critical importance for organizations to design HR policies and practices to enhance employees' ability to identity and process knowledge, organizations should also focus on how they can facilitate employees to leverage and utilize acquired knowledge (i.e., realized AC), which then drives creativity. In many cases, organizations pay most attention to the search for new ideas and knowledge, but do not have enough focus on the need for knowledge utilization and exploitation within the organization. Organizations must take coherent action to pursue both of these abilities. For example, organizations can utilize training to develop employees' confidence capability to apply newly acquired knowledge, and managers' capability to provide necessary support for new knowledge utilization. Also through training, organizations should focus on train managers to become transformational or participative leaders who can have a positive influence on employees' sense of psychological safety by encouraging their active involvement and reducing the perceived risk of exploring and applying new knowledge at work (Newman et al., 2017). Furthermore, 
organizations should focus on job design strategies that create opportunities for employees to exchange and apply new knowledge within and beyond their current work areas, such as job rotation and cross-team/functional interfaces.

Finally, we show that employee creativity is likely to lead to superior job performance, reinforcing the practical value of research examining the outcomes of employee creativity. This implies that organizations can reap the benefits of employee creativity by identifying and creating conditions to develop creative individuals through relevant organizational practice (e.g., training and development and job design).

\section{Limitations and directions for future research}

There are several limitations to this study. First, our data were collected within a single organization. Although this helped control for confounding variables across companies and industries, generalizations of our results must be made with caution. Future research could

collect data from other organizations and industries, since organizational and industry factors can influence how employees respond to various forms of motivation. Nonetheless, our sample is a useful source for this study because of the typically heavy job demands and strong need for creativity. Second, similar to Gong et al. (2009) and Zhang and Bartol (2010), our data were collected in the Chinese context, we agree with these authors that future studies should replicate our findings in other cultures to ensure generalizability. In addition, we emphasize the need to pay more attention to individual differences and its effect on knowledge processes. Future research can examine how personal traits may moderate the relationships between motivation factors and knowledge sharing activities. Finally, we collected supervisor rated creativity and job performance at the same time point. While the use of other rated outcomes reduces the issue of common method bias, the use of the same source of both outcome variables might have inflated the estimation of the relationship between the two. Future research needs to consider 
the use of time lagged data and a combination subjective and objective performance data to allow for clearer conclusions concerning causality between creativity and job performance.

\section{Conclusion}

We proposed and empirically tested a model of individual level AC, investigating its antecedents and its impact on creativity and job performance. Our results highlight three central findings. First, we demonstrated that individuals' intrinsic motivation (after controlling for extrinsic motivation) and their perception of organizational commitment to learn influence their willingness in engaging in potential AC. Our results also confirmed, at the individual level, the potential AC-realized AC-performance relationship, as proposed by Zahra and George (2002) at the organizational level. In addition, we uncovered an important finding by demonstrating that high levels of RAC enable employees to better leverage their knowledge in the form of increased creativity. Third, we contribute to an important gap in the creativity literature by demonstrating the positive relationship between employee creativity and job performance. 


\section{References}

Amabile, T. M. (1996), Creativity in Context: Update to "The Social Psychology of Creativity", Westview Press, Boulder, CO.

Anderson, N., Potočnik, K. and Zhou, J. (2014), "Innovation and creativity in organizations a state-of-the-science review, prospective commentary, and guiding framework", Journal of Management, Vol. 40 No. 5, pp. 1297-1333.

Aguinis, H. (2009). Performance Management. Upper Saddle River, NJ: Pearson Prentice Hall.

Baker, W. E. and Sinkula, J. M. (1999), "The synergistic effect of market orientation and learning orientation on organizational performance", Journal of the Academy of Marketing Science, Vol. 27 No. 4, pp. 411-427.

Baron, R. M. and Kenny, D. A. (1986), "The moderator-mediator distinction in social psychological research: Conceptual, strategic, and statistical considerations", Journal of Personality and Social Psychology, Vol. 51, pp. 1173-1182.

Bock, G. W., Zmud, R. W., Kim, Y. G. and Lee, J. N. (2005), "Behavioral intention formation in knowledge sharing: Examining the roles of extrinsic motivators, social-psychological forces, and organizational climate", MIS Quarterly, Vol. 29 No. 1, pp. 87-111.

Cabrera, E. F. and Cabrera, A. (2005), "Fostering knowledge sharing through people management practices", The International Journal of Human Resource Management, Vol. 16 No. 5, pp. 720-735.

Calantone, R. J., Cavusgil, S. T. and Zhao, Y. (2002), "Learning orientation, firm innovation capability, and firm performance", Industrial Marketing Management, Vol. 31 No. 6, pp. 515-524.

Chang, S., Gong, Y., Way, S. A. and Jia, L. (2013), "Flexibility-oriented HRM systems, absorptive capacity, and market responsiveness and firm innovativeness", Journal of Management, Vol. 39 No. 7, pp. 1924-1951.

Cohen, W. M. and Levinthal, D. A. (1990), "Absorptive capacity: a new perspective on learning and innovation", Administrative Science Quarterly, Vol. 35 No. 1, pp. 128-152.

Deci, E. L., \& Ryan, R. M. (2012), "Self-determination theory”, in Van Lange, P. A. M. , Kruglanski, A. W. and Higgins E. T. (Eds.) Handbook of Theories of Social Psychology (Vol.1). Sage, Thousand Oaks, CA, pp. 416-437.

Flatten, T., Adams, D. and Brettel, M. (2015), "Fostering absorptive capacity through leadership: A cross-cultural analysis", Journal of World Business, Vol. 50 No. 3, pp. 519534.

Foss, N. J. (2011), "Invited Editorial: Why micro-foundations for resource-based theory are needed and what they may look like", Journal of Management, Vol. 37 No. 5, pp. 14131428.

Foss, N. J., Minbaeva, D. B., Pedersen, T. and Reinholt, M. (2009), "Encouraging knowledge sharing among employees: How job design matters", Human Resource Management, Vol. 48 No. 6, pp. 871-893.

Gagné, M. (2009), "A model of knowledge-sharing motivation", Human Resource Management, Vol. 48 No. 4, pp. 571-589.

Gagné, M. and Deci, E. L. (2005), "Self-determination theory and work motivation", Journal of Organizational behavior, Vol. 26 No. 4, pp. 331-362.

George, J. M. and Zhou, J. (2002), "Understanding when bad moods foster creativity and good ones don't: the role of context and clarity of feelings", Journal of Applied Psychology, Vol. 87 No. 4, pp. 687-697. 
Gilson, L. L. (2008), "Why be creative: A review of the practical outcomes associated with creativity at the individual, group, and organizational levels", in Zhou, J. and Shalley, C. E. (Eds.) Handbook of Organizational Creativity, Erlbaum, Mahwah, NJ, pp. 303-322.

Gong, Y., Huang, J.-C. and Farh, J.-L. (2009), "Employee learning orientation, transformational leadership, and employee creativity: The mediating role of employee creative selfefficacy", Academy of Management Journal, Vol. 52 No. 4, pp. 765-778.

Gong, Y., Zhou, J. and Chang, S. (2013), "Core knowledge employee creativity and firm performance: The moderating role of riskiness orientation, firm size, and realized absorptive capacity", Personnel Psychology, Vol. 66 No. 2, pp. 443-482.

Hart, T. A., Gilstrap, J. B. and Bolino, M. C. (2016), "Organizational citizenship behavior and the enhancement of absorptive capacity", Journal of Business Research, Vol. 69 No. 10, pp. 3981-3988.

Hirst, G., Van Knippenberg, D., Chen, C.-h. and Sacramento, C. A. (2011), "How does bureaucracy impact individual creativity? A cross-level investigation of team contextual influences on goal orientation-creativity relationships", Academy of Management Journal, Vol. 54 No. 3, pp. 624-641.

Hirst, G., Van Knippenberg, D. and Zhou, J. (2009), "A cross-level perspective on employee creativity: Goal orientation, team learning behavior, and individual creativity", Academy of Management Journal, Vol. 52 No. 2, pp. 280-293.

Hotho, J. J., Becker-Ritterspach, F. and Saka-Helmhout, A. (2012), "Enriching absorptive capacity through social interaction", British Journal of Management, Vol. 23 No. 3, pp. 383-401.

Jansen, J. J. P., Van Den Bosch, F. A. J. and Volberda, H. W. (2005), "Managing potential and realized absorptive capacity: how do organizational antecedents matter?", The Academy of Management Journal, Vol. 48 No. 6, pp. 999-1015.

Kozlowski, S. W. J. and Klein, K. J. (2000), "A multilevel approach to theory and research in organizations: Contextual, temporal, and emergent processes", in Klein, K. J. and Kozlowski, S. W. J. (Eds.) Multilevel Theory, Research, and Methods in Organizations: Foundations, extensions, and new directions, Jossey-Bass, San Francisco, CA, pp. 3-90.

Kukenberger, M. R., Mathieu, J. E. and Ruddy, T. (2015), "A cross-level test of empowerment and process influences on members' informal learning and team commitment", Journal of Management, Vol. 41 No. 3, pp. 987-1016.

Kuvaas, B. (2007), "Different relationships between perceptions of developmental performance appraisal and work performance", Personnel Review, Vol. 36 No. 3, pp. 378-397.

Lane, P. J., Koka, B. R. and Pathak, S. (2006), "The reification of absorptive capacity: a critical review and rejuvenation of the construct", The Academy of Management Review, Vol. 31 No. 4, pp. 833-863.

Lewin, A. Y., Massini, S. and Peeters, C. (2011), "Microfoundations of internal and external absorptive capacity routines", Organization Science, Vol. 22 No. 1, pp. 81-98.

Li, Y., Guo, H., Yi, Y. and Liu, Y. (2010), "Ownership concentration and product innovation in Chinese firms: The mediating role of learning orientation", Management and Organization Review, Vol. 6 No. 1, pp. 77-100.

Martinaityte, I. and Sacramento, C. A. (2013), "When creativity enhances sales effectiveness: The moderating role of leader-member exchange", Journal of Organizational Behavior, Vol. 34 No. 7, pp. 974-994.

Martinkenaite, I. and Breunig, K. J. (2016), "The emergence of absorptive capacity through micro-macro level interactions", Journal of Business Research, Vol. 69 No. 2, pp. 700708. 
Mavondo, F. T., Chimhanzi, J. and Stewart, J. (2005), "Learning orientation and market orientation: relationship with innovation, human resource practices and performance", European Journal of Marketing, Vol. 39 No. 11/12, pp. 1235-1263.

Minbaeva, D., Pedersen, T., Björkman, I., Fey, C. F. and Park, H. J. (2003), "MNC knowledge transfer, subsidiary absorptive capacity, and HRM", Journal of International Business Studies, Vol. 34 No. 6, pp. 586-599.

Minbaeva, D. B., Mäkelä, K. and Rabbiosi, L. (2012), "Linking HRM and knowledge transfer via individual-level mechanisms", Human Resource Management, Vol. 51 No. 3, pp. 387405.

Minbaeva, D. B., Pedersen, T., Björkman, I. and Fey, C. F. (2014), "A retrospective on: MNC knowledge transfer, subsidiary absorptive capacity, and HRM", Journal of International Business Studies, Vol. 45 No. 1, pp. 52-62.

Newman, A., Donohue, R., and Eva, N. (2017), "Psychological safety: A systematic review of the literature", Human Resource Management Review, Vol. 27 No. 3, pp. 521-535.

Preacher, K. J. and Hayes, A. F. (2008), "Asymptotic and resampling strategies for assessing and comparing indirect effects in multiple mediator models", Behavior Research Methods, Vol. 40, pp. 879-891.

Reinholt, M., Pedersen, T. and Foss, N. J. (2011), "Why a central network position isn't enough: The role of motivation and ability for knowledge sharing in employee networks", Academy of Management Journal, Vol. 54 No. 6, pp. 1277-1297.

Rosenthal, T. L., \& Zimmerman, B. J. (2014). Social Learning and Cognition. Academic Press, New York, NY.

Rucker, D. D., Preacher, K. J., Tormala, Z. L. and Petty, R. E. (2011), "Mediation analysis in social psychology: Current practices and recommendations", Social and Personality Psychology Compass, Vol. 5/6, pp. 359-371.

Ryan, R. M. and Deci, E. L. (2000), "Intrinsic and extrinsic motivations: Classic definitions and new directions", Contemporary Educational Psychology, Vol. 25 No. 1, pp. 54-67.

Shrout, P. E. and Bolger, N. (2002), "Mediation in experimental and nonexperimental studies: New procedures and recommendations", Psychological Methods, Vol. 7, pp. 422-445.

Sinkula, J. M., Baker, W. E. and Noordewier, T. (1997), "A framework for market-based organizational learning: Linking values, knowledge, and behavior", Journal of the Academy of Marketing Science, Vol. 25 No. 4, pp. 305-318.

Soo, C., Devinney, T., Midgley, D. and Deering, A. (2002), "Knowledge management: philosophy, processes, and pitfalls", California Management Review, Vol. 44 No. 4, pp. 129-150.

Soo, C., Tian, A. W., Teo, S. T. and Cordery, J. (2016), "Intellectual capital-enhancing HR, absorptive capacity, and innovation", Human Resource Management. doi: 10.1002/hrm.21783

Tierney, P., Farmer, S. M. and Graen, G. B. (1999), "An examination of leadership and employee creativity: The relevance of traits and relationships", Personnel Psychology, Vol. 52 No. 3, pp. 591-620.

Tortoriello, M. (2015), "The social underpinnings of absorptive capacity: The moderating effects of structural holes on innovation generation based on external knowledge", Strategic Management Journal, Vol. 36 No. 4, pp. 586-597.

Volberda, H. W., Foss, N. J. and Lyles, M. A. (2010), "Absorbing the concept of absorptive capacity: How to realize its potential in the organization field", Organization Science, Vol. 21 No. 4, pp. 931-951.

Williams, L. J., and Anderson, S. E. (1991), "Job satisfaction and organizational commitment as predictors of organizational citizenship and in-role behaviors," Journal of Management, Vol. 17 No. 3, pp. 601-617. 
Yao, F. K. and Chang, S. (2017), "Do individual employees' learning goal orientation and civic virtue matter? A micro-foundations perspective on firm absorptive capacity", Strategic Management Journal. doi: 10.1002/smj.2636

Zahra, S. A. and George, G. (2002), "Absorptive capacity: A review, reconceptualization, and extension", The Academy of Management Review, Vol. 27 No. 2, pp. 185-203.

Zhang, X. and Bartol, K. M. (2010a), "The influence of creative process engagement on employee creative performance and overall job performance: A curvilinear assessment", Journal of Applied Psychology, Vol. 95 No. 5, pp. 862-873.

Zhang, X. and Bartol, K. M. (2010b), "Linking empowering leadership and employee creativity: The influence of psychological empowerment, intrinsic motivation, and creative process engagement", Academy of Management Journal, Vol. 53 No. 1, pp. 107-128.

Zhou, J. and Shalley, C. E. (2011), "Deepening our understanding of creativity in the workplace: A review of different approaches to creativity research", in Zedeck, S. (Ed.) APA Handbook of Industrial and Organizational Psychology, APA, Washington, DC, pp. 275-302. 
Table 1

Descriptive statistics among research variables $^{a}$

\begin{tabular}{|c|c|c|c|c|c|c|c|c|c|c|c|c|c|c|c|c|}
\hline Variable & Mean & SD & 1 & 2 & 3 & 4 & 5 & 6 & 7 & 8 & 9 & 10 & 11 & 12 & 13 & 14 \\
\hline 1. Gender & 1.77 & 0.42 & & & & & & & & & & & & & & \\
\hline 2. Age & 2.14 & 0.50 & -.07 & & & & & & & & & & & & & \\
\hline 3. Tenure & 1.38 & 9.11 & -.04 & .04 & $(.88)$ & & & & & & & & & & & \\
\hline 4. Education & 0.84 & 9.03 & -.05 & .05 & .00 & & & & & & & & & & & \\
\hline 5. Anticipated reciprocal benefits & 3.73 & 0.55 & .08 & .14 & -.01 & -.06 & & & & & & & & & & \\
\hline 6. Anticipated extrinsic reward & 3.08 & 0.67 & -.02 & .04 & -.08 & .12 & $.27 * *$ & $(.79)$ & & & & & & & & \\
\hline 7. Proactive personality & 5.15 & 0.97 & -.04 & .09 & .02 & .01 & $.32 * *$ & .05 & $(.80)$ & & & & & & & \\
\hline 8. Self-efficacy & 5.11 & 1.04 & -.03 & .13 & .05 & -.02 & $.24 * *$ & .05 & $.74 * *$ & $(.89)$ & & & & & & \\
\hline 9. Intrinsic motivation & 5.57 & 0.76 & -.03 & .07 & .03 & .00 & $.28 * *$ & .11 & $.43^{* *}$ & $.48 * *$ & $(.72)$ & & & & & \\
\hline $\begin{array}{l}\text { 10. Organizational commitment to } \\
\text { learning }\end{array}$ & 5.28 & 1.08 & -.03 & -.01 & -.05 & .02 & $.22^{*}$ & $.21 *$ & $.23^{* *}$ & $.26^{* *}$ & $.42^{* *}$ & $(.87)$ & & & & \\
\hline 11. PAC & 4.67 & 0.80 & -.04 & .13 & .07 & -.02 & $.33 * *$ & .11 & $.51 * *$ & $.53 * *$ & $.51 * *$ & $.39 * *$ & $(.79)$ & & & \\
\hline 12. RAC & 3.67 & 0.49 & -.05 & .25 & .05 & .01 & $.41 * *$ & $.20 *$ & $.39 * *$ & $.43 * *$ & $.28 * *$ & $.21 *$ & $.51 * *$ & $(.89)$ & & \\
\hline 13. Creativity & 3.67 & 0.37 & .08 & .09 & -.04 & -.03 & $.50 * *$ & $.32 * *$ & $.29 * *$ & $.19^{*}$ & $.25^{* *}$ & $.19^{*}$ & $.27 * *$ & $.56^{* *}$ & $(.93)$ & \\
\hline 14. Job performance & 5.24 & 0.90 & .05 & .16 & .11 & .00 & $.32 * *$ & .00 & $.52 * *$ & $.57 * *$ & $.56^{* *}$ & $.33 * *$ & $.72 * *$ & $.55^{* *}$ & $.30 * *$ & (.91) \\
\hline
\end{tabular}

${ }^{\mathrm{a}}$ Note: ${ }^{*} p<.05,{ }^{* *} p<.01, \mathrm{n}=125$

Cronbach's coefficient alpha is provided along the diagonal in parentheses. 
Table 2

Results of Hierarchical Regression Analysis for PAC and Job Performance

\begin{tabular}{|c|c|c|c|c|c|c|}
\hline \multirow{2}{*}{ Variables } & \multicolumn{2}{|c|}{ PAC } & \multicolumn{4}{|c|}{ Job performance } \\
\hline & Model 1 & Model 2 & Model 3 & Model 4 & Model 5 & Model 6 \\
\hline \multicolumn{7}{|l|}{ Control variables } \\
\hline Gender & -.07 & -.04 & .05 & .05 & .07 & .07 \\
\hline Age & .07 & .09 & .06 & .06 & .01 & .01 \\
\hline Job tenure & .004 & .01 & .07 & .07 & .06 & .06 \\
\hline Education & -.001 & -.001 & .02 & .03 & .02 & .02 \\
\hline Proactive personality & $.16^{+}$ & .14 & .17 & .14 & .15 & .15 \\
\hline Self-efficacy & $.26^{* *}$ & $.17^{+}$ & $.36 * *$ & $.36 * * *$ & $.26 * *$ & $.26 * *$ \\
\hline Anticipated extrinsic reward & .05 & .003 & -.07 & -.10 & -.10 & -.10 \\
\hline Anticipated reciprocal benefits & $.25^{*}$ & .17 & $.16^{*}$ & .11 & .07 & .07 \\
\hline \multicolumn{7}{|l|}{ Independent variable } \\
\hline Intrinsic motivation & & $.24^{* *}$ & & & & \\
\hline Organizational commitment to learn & & $.13^{*}$ & & & & \\
\hline Creativity & & & & $.13^{+}$ & -.10 & .02 \\
\hline \multicolumn{7}{|l|}{ Moderation } \\
\hline $\mathrm{RAC}$ & & & & & $.32^{* * * *}$ & $.37^{* * * *}$ \\
\hline RAC x Creativity & & & & & & -.06 \\
\hline $\mathrm{R}^{2}$ & $.35^{* * *}$ & $.44^{* * *}$ & $.39^{* * * *}$ & $.41^{+}$ & $.48^{* * *}$ & .48 \\
\hline$\Delta \mathrm{R}^{2}$ & & $.09^{* * *}$ & & $.02^{+}$ & $.07^{* * *}$ & .00 \\
\hline $\mathrm{F}$ for increment in $\mathrm{R}^{2}$ & & $8.78^{* * *}$ & & $2.93^{+}$ & $15.16^{* * *}$ & .01 \\
\hline
\end{tabular}




\section{Table 3}

Results of Hierarchical Regression Analysis for Mediation Analysis

\begin{tabular}{lcccc}
\hline \multicolumn{1}{c}{ Variables } & $\beta$ & s.e. & $\mathrm{t}$ & $\mathrm{p}$ \\
\hline Step 1: RAC & & & & \\
$\quad$ PAC & .30 & .05 & 6.14 & $<.001$ \\
Step 2: Creativity & & & & \\
$\quad$ PAC & .12 & .04 & 2.96 & $<.01$ \\
Step 3: Creativity & & & & \\
$\quad$ PAC & -.01 & .04 & -.20 & .84 \\
$\quad$ RAC & .44 & .07 & 6.52 & $<.001$ \\
\hline
\end{tabular}

